\section{Where science has gone wrong}

SIR-The following are brief answers to some of the published objections (330, 308, 689-690; 1987 \& 331, 129-130, 204, $384,558 ; 1988)$ to our Commentary article $(\mathbf{3 2 9}, 595-598 ; 1987)$. The article was misinterpreted as an attack against philosophy, sociology and the human sciences, allegedly to preserve the prestige and privileges of the natural sciences. But the 'human' sciences are as scientific as the 'natural' sciences, and the allegation itself is also capable of being assessed objectively.

It is true that Popper and Feyerabend differ in many respects. But it is unfair to single out Feyerabend as worse than the others. For he too sets out to do what he sincerely believes is best for society. This he does by declaring "Anything goes", a position that follows inescapably from the (popperian) premise that all observations are theory-laden. This premise is the most basic of all errors, and the writings of those who commit it are bound to be a hopeless muddle. If Popper, Kuhn and their followers do not like being called relativists, negativists and irrationalists, then they ought to repudiate this worst of all antitheses.

A frequent and passionate objection was to the dogmatic way in which we express some views. We never cease to be amazed by the frequency and vehemence of this objection - how can anyone seriously say with such passion anything at all if one does not have complete confidence in what one says? The reason why so many people are horrified by dogmatism is obviously because many instances in the past caused much harm. But in all these cases harm was done because what

\section{Access to journals}

SIR-The letter from Edward D. Goldberg (Nature 332, 10; 1988) emphasizes an important problem in the area of scientific communication among its practitioners. Although international agencies may be able to help alleviate the shortage of scientific journals in certain countries, they may not be able to do so in the near future. A voluntary effort by concerned scientists in North America and Western Europe might perhaps prove to be more useful.

It is common for working scientists to subscribe to one or more scientific journals, one general and one specialized. It is far too common for these journals to be thrown away after one year on the shelf. Certainly, every summer, in the medical school building at this university, corridors are lined with discarded copies of Science, New England Journal of Medicine and Cancer Research, to name a few. It should be possible for us to 'adopt' an institution with limited journal holdings to people were dogmatic about was not true. If what one is dogmatic about is true, this dogmatism cannot possibly be harmful.

How can one be certain that one knows the truth? This is often difficult to answer. But we suggest that this is the very question that every professional (not only scientists and philosophers but also historians, physicians, journalists, police officers and so on) ought to be trying to answer, instead of denying the very existence of truth. If one does not do so, this conduct should be seen for what it really is: a breach of professional duty. The question is whether on the available evidence a hypothesis has been refuted, or verified (and how accurately), or is still open to further investigation. In the latter case one has to be sceptical, in the former dogmatic.

It would be irrational, and probably harmful, not to be dogmatic in one's advocacy of a proven truth. A good example may illustrate this point: Consider the proposition that "when ingested, 0.3 grams of sodium cyanide will rapidly kill a person". We believe that this is true, we are absolutely certain about it, and we are dogmatic about it. We invite those critics who think that our dogmatism is wrong and dangerous to refute it.

It was also objected that science attained its present level without much self-analysis, and that most major breakthroughs were apparently made by accident, chance, serendipity or at best with Popper's prescription of 'trial and error', 'hit and miss', 'conjecture and refutation' methodology. But what is this, if not the methodology of the Stone Age? To those who wish to move forward and

which most of the year-old scientific journals from a given university might be mailed. One-year-old scientific journals are better than none at all.

SALEEM JaHANGEer

Institute for Disease Prevention,

George Washington University Medical Center,

2300 Eye Street, $N W$,

Washington, DC 20037, USA

\section{Risks of AIDS}

SIR-In a news item "AIDS and public opinion in France" (Nature 332, 295; 1988), we were invited to wonder that "even those with a baccalaureate . . f felt that human immunodeficiency virus (HIV) could be transmitted by mosquitoes [or] dental instruments ....". The probability of transmission by sexual contact is of the order of one in 10 . What is the working definition of "could be transmitted" - one in $10^{4}$ ? $10^{7}$ ? Surely the answer must depend on the size of the make progress, we would recommend much more serious self-analysis and forward planning. The last objection is only partly correct, and for a fuller picture we recall the old saying "luck favours the prepared" and Rutherford's famous dictum "an ounce of thought is worth a ton of equipment".

Nature's hostility towards 'creation science' was recently rebuked in these terms: "Creationism is no more untenable a concept than the postulate of modern physics that matter can be created from nothing"! While we have no dogmatic opinion as to how the Universe originated, we are fairly certain that 'matter can be created from nothing' is not a true postulate of physics. In fact the epistemological antitheses to some extent owe their resurgence in the twentieth century to this and other alleged 'postulates of modern physics' of a similar nature. But these 'postulates' do not follow from any rational study of the evidence, and, contrary to what was suggested, there seem to be a few things wrong with modern physics. The sooner these errors are corrected, the sooner people will be able to see through the fallacies of the antitheses, of creationism, the paranormal and so on. It also appears that these errors in physics were the result of the physicists' poor grasp of the scientific method. For these errors are the 'solutions' of certain scientific problems arrived at by applying not the scientific method as such but instead the theological method of the Christian religion ${ }^{2}$.

T. THEOCHARIS M. Psimopoulos

The Blackett Laboratory

Imperial College,

London SW7 2BZ, UK

Chelvam, R. T. Nature 331, 10 (1988)

2. Stannard, R. The Times, 3 December 1983.

population facing a minor exposure threat and subjective factors. Where are the data to verify the null hypothesis to such accuracy for these not implausible transmission routes? Would the designer of the French questionnaire really put a contaminated dental instrument in his mouth?

It is as irresponsible here as in nuclear power safety for scientists to assert that events of small or indeterminate probability cannot happen. The larger issue is the level of conflict between the civil and human rights of AIDS sufferers and the rights of the complement to avoid exposure. It serves no useful purpose to pretend the answer is zero. I hope it is an underestimate of human goodwill and tolerance that unless we are convinced the answer is zero, the rights and needs of both groups cannot be substantially accommodated.

\title{
Department of Mathematics,
}

Michael H. Freedman

University of California, San Diego, La Jolla, California 92093-0112, USA 